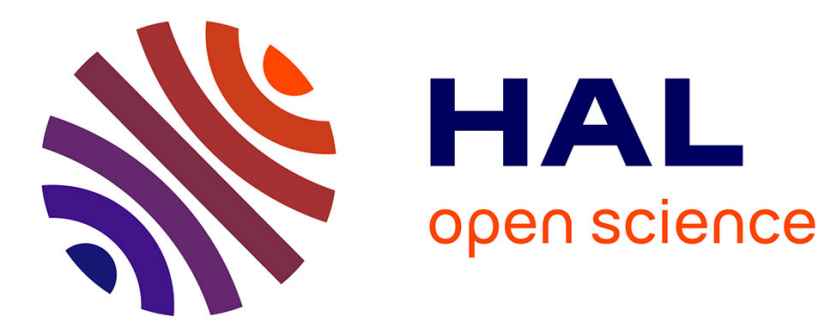

\title{
Semiology and Epileptic Networks
}

Aileen Mcgonigal

\section{To cite this version:}

Aileen Mcgonigal. Semiology and Epileptic Networks. Neurosurgery Clinics of North America, 2020, 31 (3), pp.373-385. 10.1016/j.nec.2020.03.003 . hal-02668419

\section{HAL Id: hal-02668419 https://hal-amu.archives-ouvertes.fr/hal-02668419}

Submitted on 31 May 2020

HAL is a multi-disciplinary open access archive for the deposit and dissemination of scientific research documents, whether they are published or not. The documents may come from teaching and research institutions in France or abroad, or from public or private research centers.
L'archive ouverte pluridisciplinaire HAL, est destinée au dépôt et à la diffusion de documents scientifiques de niveau recherche, publiés ou non, émanant des établissements d'enseignement et de recherche français ou étrangers, des laboratoires publics ou privés. 


\title{
Semiology and Epileptic Networks
}

\author{
Aileen McGonigal, MD, PhD ${ }^{a, b}$
}

\section{KEYWORDS}

- Semiology • Seizure • Stereoelectroencephalography • SEEG • Epileptic networks • Stereotypies

\section{KEY POINTS}

- Seizure semiology represents the dynamic clinical expression of seizures and is an important data source providing clues to cerebral organization.

- Seizure semiology is produced through interactions between seizure onset and propagation within physiologic and pathologic brain networks.

- Semiology can be described in spatial and temporal terms, and depends on both spatial and temporal characteristics of cerebral electrical activity.

- Stereoelectroencephalography studies of electroclinical correlations, including with quantified signal analysis, have helped elucidate several semiological patterns.

- Future research could help improve pattern recognition of complex semiological patterns, possibly using deep learning methods in a multiscale, multimodal modelization framework.

\section{INTRODUCTION}

Epileptic seizures caused by abnormal cerebral electrical discharge may be symptomatic or asymptomatic, an observation readily apparent from electroencephalography (EEG) recording, especially when using depth electrodes. Epileptic seizures are experienced only through their tangible semiological expression, which represents the patient's main symptomatic burden: transient effects such as subjective sensations, altered consciousness, motor signs, and behavioral change, eventually influenced by the particular environmental setting and circumstances of the seizure, whether any communication takes place with the patient during the seizure, and so on. Seizure semiology thus represents a complex interaction between brain, body, and environment, which is caused by more or less direct transient alteration of cerebral network dynamics. Semiology might be thought of as the embodiment of the seizure. As a behavioral data source, its study could even be conceptualized within a long tradition of phenomenological enquiry ${ }^{1-3}$ as well as the more recently proposed framework of embodied cognition. ${ }^{4}$

Considering epilepsy as a network disorder, ${ }^{5-7}$ seizures and their semiological expression represent complex dynamical systems ${ }^{8}$ that can be described in spatial and temporal terms. The currently optimal tool for exploration of these is stereoelectroencephalography (SEEG), because of its ability to simultaneously explore lateral and mesial regions in a multilobar distribution with millisecond temporal resolution. There is a bidirectional and sometimes ambiguous relationship between semiology and SEEG: semiology is a key feature in formulating hypotheses of the epileptogenic zone (EZ) and thus helps in defining implantation strategy, but the SEEG is also a necessary tool for investigating the neural basis of semiology, many aspects of which remain elusive.

\section{THE PARADOX OF SEMIOLOGY}

A paradox exists regarding the localizing value of seizure semiology. On one hand, since the advent

\footnotetext{
a Aix Marseille Univ, INSERM, INS, Inst Neurosci Syst, Marseille, France; ${ }^{b}$ APHM, Timone Hospital, Epileptology and cerebral rythmology, Marseille, France

E-mail address: aileen.mcgonigal@univ-amu.fr
} 
of EEG, semiology has continuously formed the basis of international clinical classification systems of seizures over the last 50 years. ${ }^{9,10}$ Semiological data are (rightly) considered essential contributions in the presurgical evaluation of focal epilepsies and in seizure classification. On the other hand, vast gaps remain in the knowledge of the neural substrates of various ictal signs, especially complex motor behaviors. As such, the localizing value of semiological expression is much more specific for some clinical patterns than others. The specificity and sensitivity of how clinical features map onto cerebral electrical activity depend on the degrees of freedom that influence how neural activity gives rise to seizure expression. This relation tends to be different in simpler elementary signs arising from primary cortex, compared with complex signs arising from associative cortex that often involve more widespread propagation. Semiological expression is also influenced by background state of neural networks (eg, sleep, drug reduction). An interesting idea for future study is that semiological expression may be influenced by genetic and molecular factors, as has begun to be elucidated for some movement disorders, ${ }^{11}$ although this has not at all yet been explored in epilepsy.

Although in certain cases semiological data can map fairly reliably to likely regions of cerebral activity, the reverse relation is much less evident: looking at an EEG trace of a seizure, it is usually not possible to predict what, if any, clinical signs may be associated and precisely when they will emerge. This observation is true even for seizures with a relatively straightforward link between electrical and clinical appearance, such as clonic jerks or absences.

\section{SEMIOLOGICAL PATTERN RECOGNITION}

The basis for semiological analysis is essentially pattern recognition by expert clinicians. Level of expertise is crucial, because this affects the likelihood of rare or subtle clinical patterns being recognized; accuracy of semiological diagnosis depends both on level of clinical expertise and complexity of clinical pattern. ${ }^{12}$ Visual analysis of seizure semiology incorporates recognition of individual signs and overall patterns; depending on seizure type, either or both of these may be more or less important.

Some semiological patterns are readily recognizable and have a high probability of mapping more or less directly to certain brain structures, regions, or at least systems. An example of this is the constellation of symptoms and signs occurring in a mesial temporal lobe seizure (eg, epigastric rising sensation, pallor, déjà vu, altered awareness, manual and/or oroalimentary automatisms, and so on), which epileptologists immediately recognize and can more or less confidently associate with high probability of cerebral localization. Other semiological patterns may be less well localizing for several reasons: (1) they manifest in much more heterogeneous and variable ways; (2) they are difficult to perceive, either because of few evident signs or, on the contrary, many signs that emerge very rapidly (eg, in some frontal seizures); (3) they do not consistently map to specific brain areas.

Several of these difficult characteristics may be present in the same seizure. Such a situation clearly has major implications for presurgical exploration strategy, because, depending on the ensemble of available data, poorly localizing semiological patterns tend to lead to more widespread, often multilobar, sampling in order to allow the various alternative hypotheses to be confirmed or refuted. Nevertheless, even complex semiological patterns can show robust correlations with cerebral data, as has been shown, for example, in frontal lobe seizures ${ }^{13}$ (see Table 3 ).

A future clinical and research goal is better definition of the spectrum of complex semiological patterns, to help improve accuracy of pattern recognition. These definitions are challenging to document scientifically. Neuroethological methods have previously been applied to investigate the so-called behavioral grammar of seizures. ${ }^{14}$ Research approaches trying to untangle the repertoire of combinations of ictal signs could be potentially be aided by methods of deep learning applied to seizure video data. ${ }^{15}$

\section{NEURAL BASIS OF SEIZURE SEMIOLOGY}

What is known so far about the neural basis of seizure semiology? It is highly likely that many, if not all, ictal clinical patterns depend not only on local cortical epileptic activity but the propagation of activity within cerebral networks. ${ }^{16}$ In many seizures, the semiology only arises when propagation from zone of seizure onset occurs. From SEEG studies, both spatial and temporal characteristics of networks influence semiological output (discussed later). Interactions between not only cortical but also subcortical networks may be crucial in influencing clinical expression. ${ }^{7,17}$ However, the inevitable sampling limitations of SEEG mean that information on seizure propagation is incomplete in terms of its relation to clinical signs.

Semiology is methodologically challenging as a data source and is much more difficult to quantify than other epileptological data (such as EEG), which has so far limited application of modelization approaches that might otherwise help advance understanding. ${ }^{18}$ In addition, the role of 
semiology may be seen as clinically less crucial for presurgical evaluation than EEG, neuroimaging, and other data, and so its investigation is not necessarily prioritized. These factors help explain why the understanding of neural substrates of seizure semiology has progressed surprisingly little, despite accessibility of increasingly precise methods of studying cerebral function. ${ }^{16}$

\section{SEMIOLOGY AS A PROPERTY OF DYNAMICAL SYSTEMS WITHIN A MULTISCALE FRAMEWORK}

Epilepsy is widely accepted to be a disorder of brain networks ${ }^{5,7}$ and a seizure may be seen as an expression of a dynamical system ${ }^{7,8}$ of which semiology is an emergent property. ${ }^{16} \mathrm{~A}$ seizure is a dynamic process defined by spatial and temporal aspects, and semiology is likewise expressed as a dynamic process with spatiotemporal characteristics.

At seizure discharge level, spatial aspects refer to anatomic structures involved, corresponding with the cerebral localization that is most often discussed with regard to semiology (Table 1). Temporal aspects refer to the architecture of the discharge in terms of its frequency, latency (time lag in occurrence between structures), and synchrony. The last 2 features can only be interpreted if spatial characteristics are known: temporal relation of cerebral activity between structures is what is important, rather than description of activity in an isolated structure.

In terms of semiology, spatial aspects may be used to describe the body segments involved, amplitude of movements, and so forth (see Table 1). Temporal aspects can relate to frequency and regularity of movements, as well as the timing of appearance of different features. For example, a mesial temporal lobe seizure, with its slow progression from aura to automatic movements to altered awareness, shows very different temporal dynamics from a prefrontal seizure manifesting explosive-onset hyperkinetic behavior.

A seizure discharge and its semiological output are thus both expressions of a dynamic system, operating at different scales ${ }^{6,19}$ (Fig. 1, see Table 1). A multiscale framework can also apply to the size of electroclinical data sources: in some situations, a single-patient approach can be useful (eg, detailed characterization of individual seizures and their variability; case-report description of a rare phenomenon), whereas for some other research questions, multipatient studies are preferred (eg, characterizing repertoire of seizures from a certain brain region; studying neural correlates of a particular clinical sign). In the future, analysis on an even larger scale (eg, data mining and machine learning using large-scale video-EEG databases) could reveal previously unrecognized patterns. ${ }^{15}$

\section{HOW DO SPATIAL AND TEMPORAL ASPECTS OF SEIZURE DISCHARGE AFFECT SEMIOLOGICAL EXPRESSION?}

Although spatial aspects of seizures (cerebral localization) are the clinician's main consideration, both spatial and temporal aspects of electrical discharge influence clinical output. A temporospatial dynamic is more apparent to the observer in some seizures than others. An evident example is John Hughlings Jackson's ${ }^{20}$ description of focal clonic seizures following a "march" from one body segment to another, ${ }^{20,21}$ with a spreading zone of cortical discharge closely related to progressive involvement of body segments. In addition, EEG recording of such seizures (unknown in Jackson's time) would likely show a temporal relation between spikes and clonic jerks. A seemingly linear relation between spatiotemporal aspects of cerebral activity and clinical expression may especially be seen in primary cortex (motor, somatosensory, auditory, or visual) seizures, which are often characterized by elementary signs (Figs. 2 and 3). However, temporal aspects of an epilepsy network can influence clinical expression independently of anatomic localization. For example, in right frontal opercular seizures, tonic facial contraction was associated with an $8-\mathrm{Hz}$ to $20-\mathrm{Hz}$ discharge in motor cortex, whereas negative motor signs occurred with $80-\mathrm{Hz}$ discharge in the same structure. ${ }^{22}$

In contrast with the linearlike relation for simpler semiologies arising from functional cortex, a different picture is seen with seizures characterized by complex behaviors, emotional change, and/or altered consciousness. Here, neural substrates typically involve associative cortex, more widespread networks, and complex dynamics. ${ }^{7,16}$ Thus, it is usually not possible to localize production of such semiology to a restricted volume of cortex, because, by definition, its emergence requires larger-scale networks to be brought into play (a process that may nevertheless be triggered from discharge within a restricted volume of cortex). The triggering of a large network from an initially restricted zone of seizure onset may commonly be seen, for example, in prefrontal seizures, reflecting rich long-distance and short-distance connectivity patterns ${ }^{23,24}$ that tightly link the seizure onset zone to the early propagation network (Fig. 4). I would argue that this concept is not the same as that of the symptomatogenic zone, defined by Rosenow and Lüders ${ }^{25}$ as "the area of cortex that, when activated by an epileptiform discharge, produces the ictal symptoms." The differences are 2- 


\begin{tabular}{|c|c|c|c|c|c|c|}
\hline Data Source & Level & Timescale & $\begin{array}{l}\text { Modes of } \\
\text { Exploration }\end{array}$ & Timescale & Spatial Features & Temporal Features \\
\hline $\begin{array}{l}\text { Cerebral } \\
\text { electrical } \\
\text { activity }\end{array}$ & $\begin{array}{l}\text { Brain: local circuit, } \\
\text { area, system, } \\
\text { whole brain }\end{array}$ & $\begin{array}{l}\text { - Microseconds to } \\
\text { minutes for } \\
\text { seizures } \\
\text { - Hours to days for } \\
\text { interictal data }\end{array}$ & $\begin{array}{l}\text { EEG, SEEG (ictal and } \\
\text { interictal) } \\
\text { Also, MRI, PET, and } \\
\text { other } \\
\text { neuroimaging } \\
\text { methods } \\
\text { (interictal) }\end{array}$ & $\begin{array}{l}\text { - Microseconds to } \\
\text { minutes for } \\
\text { seizures } \\
\text { - Hours to days for } \\
\text { interictal data }\end{array}$ & $\begin{array}{l}\text { Anatomic structures } \\
\text { involved in seizure } \\
\text { discharge: onset } \\
\text { and propagation }\end{array}$ & $\begin{array}{l}\text { Discharge features: } \\
\text { - Frequency } \\
\text { - Time lag between } \\
\text { structures } \\
\text { - Synchrony changes } \\
\text { between signals in } \\
\text { different } \\
\text { structures } \\
\end{array}$ \\
\hline $\begin{array}{l}\text { Seizure } \\
\text { semiology }\end{array}$ & $\begin{array}{l}\text { Body, mind, } \\
\text { environment: } \\
\text { cognition, } \\
\text { emotions, } \\
\text { movement, } \\
\text { behavior } \\
\text { (including social } \\
\text { interaction, use of } \\
\text { objects) }\end{array}$ & $\begin{array}{l}\text { - Usually seconds to } \\
\text { minutes for } \\
\text { seizures } \\
\text { - Sometimes hours } \\
\text { for preictal and } \\
\text { postictal changes } \\
\text { - Days to years for } \\
\text { interictal data (eg, } \\
\text { interictal psychiat- } \\
\text { ric or cognitive } \\
\text { disturbance) }\end{array}$ & $\begin{array}{l}\text { Direct clinical } \\
\text { observation and } \\
\text { patient report of } \\
\text { ictal and interictal } \\
\text { symptoms and } \\
\text { signs; video and } \\
\text { audio recording of } \\
\text { seizures; } \\
\text { sometimes } \\
\text { quantitative } \\
\text { analysis (eg, } \\
\text { accelerometry, } \\
\text { automated video } \\
\text { analysis); recording } \\
\text { of other physical } \\
\text { parameters (eg, } \\
\text { ECG, EMG) }\end{array}$ & $\begin{array}{l}\text { - Usually seconds to } \\
\text { minutes for } \\
\text { seizures } \\
\text { - Sometimes hours } \\
\text { for preictal and } \\
\text { postictal changes } \\
\text { - Days to years for } \\
\text { interictal data (eg, } \\
\text { psychiatric } \\
\text { disturbance) }\end{array}$ & $\begin{array}{l}\text { Body segments } \\
\text { involved (eg, axial, } \\
\text { proximal vs distal, } \\
\text { left vs right, upper } \\
\text { vs lower) } \\
\text { Displacement of } \\
\text { body in space (eg, } \\
\text { direction, } \\
\text { amplitude) }\end{array}$ & $\begin{array}{l}\text { - Timing of appear- } \\
\text { ance of different } \\
\text { signs within same } \\
\text { seizure } \\
\text { - Duration of signs } \\
\text { - Frequency and } \\
\text { regularity of } \\
\text { repeated move- } \\
\text { ments (eg, rocking, } \\
\text { tapping) }\end{array}$ \\
\hline
\end{tabular}

Abbreviations: ECG, electrocardiogram; EMG, electromyogram. 


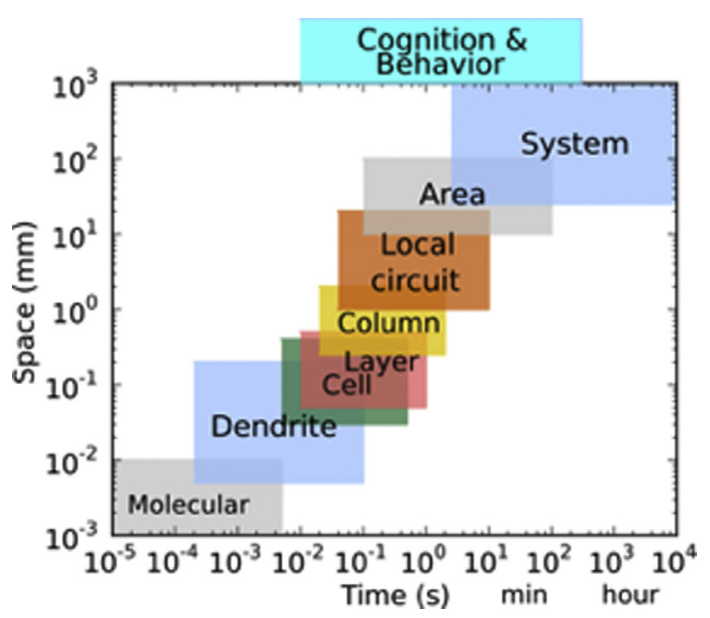

Fig. 1. Temporal and spatial scales of organization in the nervous system. Here, local area, circuit, and system levels apply both to cerebral epileptic activity and to semiological expression. (From Lytton WW, Arle J, Bobashev G, et al. Multiscale modeling in the clinic: diseases of the brain and nervous system. Brain Inform. 2017;4(4):221.)

fold: (1) as discussed, not only spatial but also temporal features of discharge affect clinical expression; (2) not only cortical but also subcortical structures likely shape clinical expression, especially in seizures with altered consciousness ${ }^{26}$ and complex motor behavior. ${ }^{17}$

\section{CORRELATING SEMIOLOGICAL PATTERNS WITH EPILEPSY NETWORKS}

Two main approaches have been used in previous SEEG studies: (1) grouping patients with a similar semiological picture or a common semiological feature and studying cerebral correlates of seizures (Table 2); (2) grouping patients with a similar anatomic organization of the $\mathrm{EZ}$ or seizures arising from a particular brain system and studying clinical correlates (Table 3). In each of these approaches, SEEG signal analysis (from the start of this century onward) has provided new insights into possible cerebral mechanisms of semiological expression. This work allowed testing of hypotheses regarding the role of neural synchronization between connected structures in producing clinical effects. ${ }^{27}$ Either increased or decreased synchronization may be seen, depending on seizure type (see Table 2).

\section{METHODOLOGICAL LIMITATIONS OF SEMIOLOGY ANALYSIS AND CORRELATION WITH STEREOELECTROENCEPHALOGRAPHY Issues of Semiological Methodology}

Optimal recording conditions are essential for extracting semiological data, including ictal examination. As well as difficulties in perception and limited knowledge of cerebral correlates, existing classification of semiological signs is to some degree inadequate ${ }^{13,28}$ and some common descriptive terms have limited meaning. For example, the term hyperkinetic seizure, as used in the current International League Against Epilepsy classification, ${ }^{10}$ implies no particular localization or cerebral substrate; both hyperkinetic and hypermotor mean only increased movement, a nonspecific feature of many seizures arising from diverse cortical localizations. Similar criticism could be applied to the term automatism, ${ }^{29}$ depending on context. These heterogeneous categories may thus not be the most useful ones when searching for meaningful neural correlates of semiology.

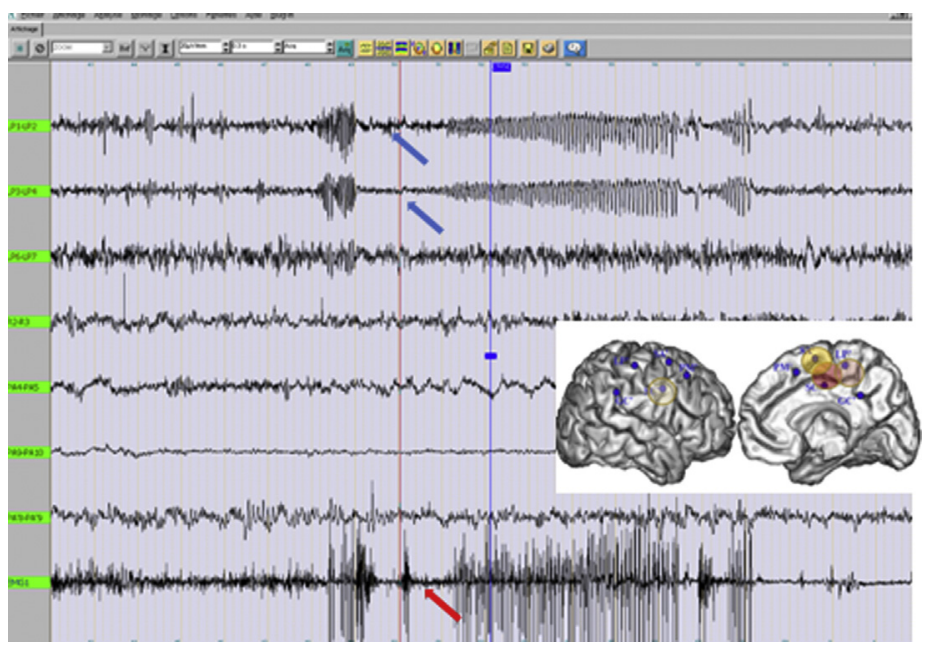

Fig. 2. SEEG recording with concomitant electromyogram (bottom trace) of a focal seizure arising from right paracentral lobule (inset) characterized by left foot paresthesia and tonic contraction. A close temporal relation can be seen between cortical epileptic activity (b/ue arrows) and left foot movements (red arrows). This nearlinear electroclinical relation is typically seen in seizures arising from primary cortex. 


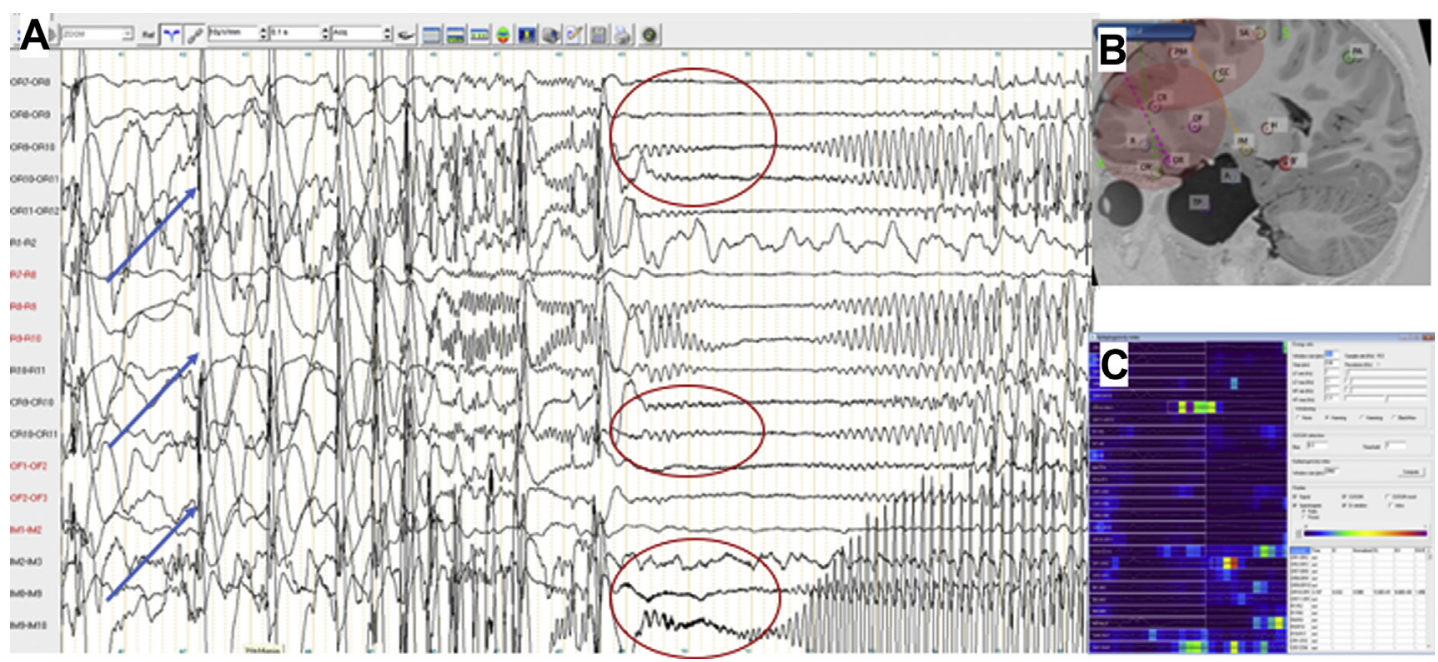

Fig. 3. (A) Seizure recorded on SEEG in a child with right frontal epilepsy, who presents left arm clonic jerks then head turning to the left. A temporal relation can be seen between clonic left arm jerks that occur simultaneously with right frontal spikes (blue arrows); these can be seen to occur synchronously across several premotor and prefrontal structures. Several seconds later, the boy presents tonic head turning to the left, contemporaneously with tonic discharge that again is visible across several structures (red circles), involving the same zone of cortex as the initial spikes. This finding shows that temporal aspects of seizure organization can influence clinical expression, rather than spatial localization alone. (B) Epilepsy organization is widespread, involving large prefrontal and premotor regions in a context of cortical malformation. (C) Quantification of rapid discharge can be useful in determining which structures play a main role. Here, the epileptogenicity index ${ }^{49}$ shows maximal values in the external contacts of the oblique OR electrode exploring right dorsolateral prefrontal cortex and in the intermediate contacts of the SA orthogonal electrode exploring right premotor cortex. This finding confirms simultaneous involvement of these structures at onset, within a widespread network.

\section{Issues of Stereoelectroencephalography Methodology}

SEEG sampling must be geared toward presurgical localization and functional evaluation; this necessarily leaves vast cortical and subcortical regions unexplored. The goal of SEEG is not to attempt exhaustive coverage of the brain, or even 1 region of the brain, because this is not realistic or safe. The objective is to achieve judicious sampling of the main structures, areas, or systems suspected to play a possible role in seizure production. Based on the clinician's knowledge of cerebral anatomy and, importantly, connectivity, activity recorded from these sampled structures is then extrapolated to form a picture of the whole. Even when sampling is optimal, the paradigm of the missing electrode should be borne in mind ${ }^{30}$ : what is seen reflects only a portion of the true picture, and epileptologists should remain vigilant to the potential importance of missing data from unexplored regions.

Choice of quantified signal analysis method for clinical and research questions can be debated, especially in conceptual terms of the relative importance of analyzing different seizure phases (eg, preictal to ictal transition, seizure onset zone, and early propagation network). Most signal analysis studies (including those listed in Table 2) have been based on data derived from seizure onset; however, another proposed approach takes into account the whole seizure dynamic, allowing differentiation of the EZ per se from secondary propagation pathways. ${ }^{31}$

\section{CONCEPTUAL ISSUES: CORTICOSUBCORTICAL NETWORKS AND SEMIOLOGICAL EXPRESSION}

Despite decades of neuroscientific research, clinicians have only limited understanding of physiologic mechanisms of behavior and consciousness. In the context of seizure semiology, it has long been postulated that circuits involving both cortical and subcortical pathways are likely to be implicated. ${ }^{32}$ This likelihood is particularly evident for seizures with altered consciousness ${ }^{26}$ and those with certain motor behaviors, especially those that have a repetitive nature and that may evoke primitive and innate behavior (eg, locomotor behavior, copulatory-type movements, emotional expression). ${ }^{33}$ Similarities between automatic motor behavior seen in both sleep disorders and frontal lobe seizures led to central pattern generators being postulated as a 


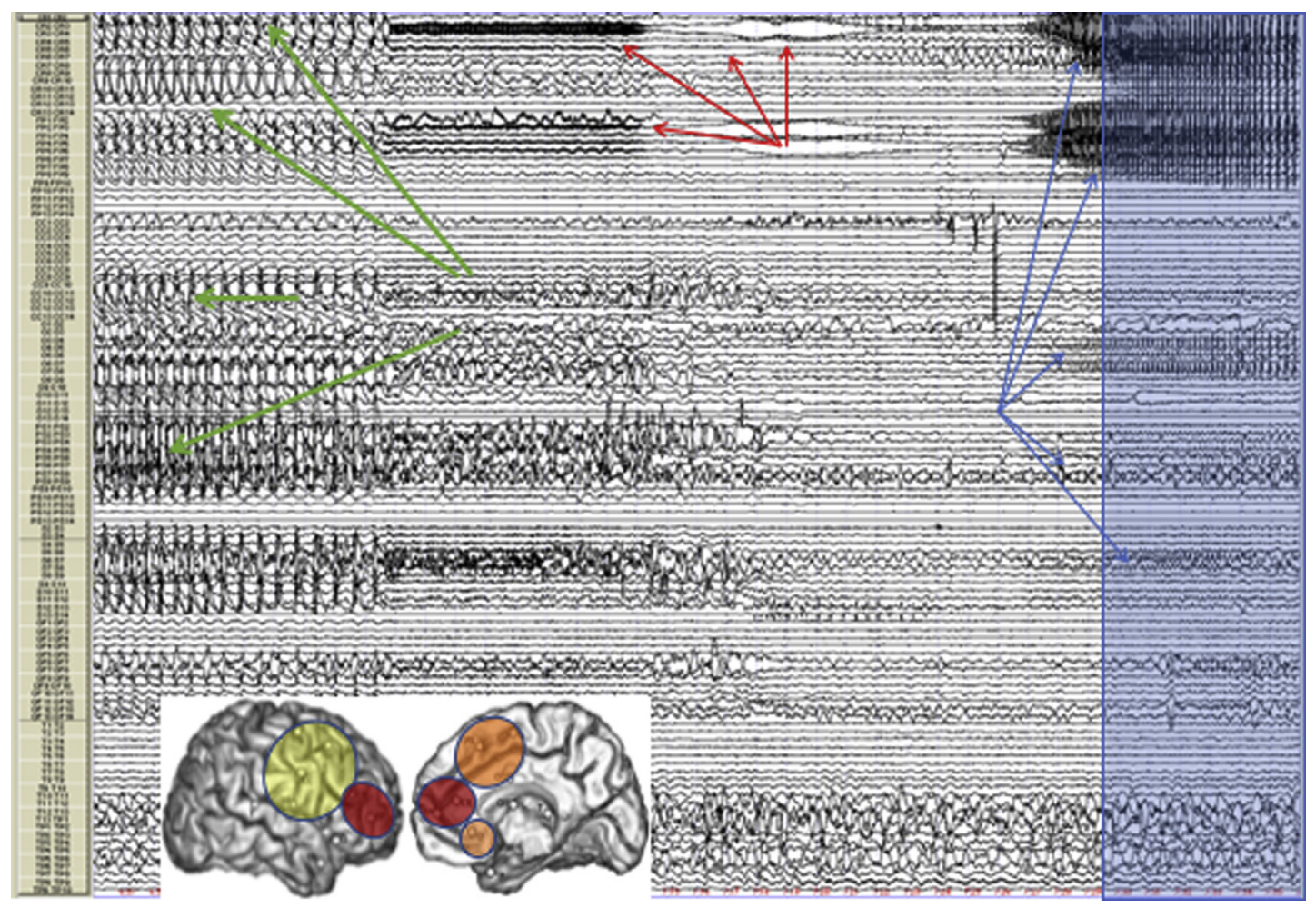

Fig. 4. Recording of a spontaneous seizure in a patient with right prefrontal type II focal cortical dysplasia (FCD). The time scale is 1 minute per page. Synchronous preictal spiking (green arrows) involves dorsolateral prefrontal cortex and anterior premotor cortex. Abrupt transition to low-voltage fast discharge occurs, initially at $20 \mathrm{~Hz}$ then $80 \mathrm{~Hz}$ (red arrows), which is maximal in anterior dorsolateral prefrontal cortex, in the perilesional zone (indicated by red circle on brain image shown in inset). The electrophysiologic pattern of preictal to ictal transition is characteristic of FCD type II. ${ }^{50}$ There is subsequently a lower-frequency spike discharge that continues to predominate in anterior prefrontal cortex but spreads to involve anterior cingulate and anterior premotor regions. Semiological signs appear around 20 seconds after start of low-voltage fast discharge (blue panel), at the time of spread of slower activity to orbital and anterior premotor regions (orange and yellow circles, inset). Despite a very tonic discharge within prefrontal cortex, the cerebral seizure remains clinically silent in this case until the phase of slower frequency propagation. This finding shows that semiological expression depends not only on zone of seizure onset but also on the early spread network, both spatially and temporally.

mechanism, ${ }^{33}$ with a semiological "fingerprint" being expressed via a final common pathway, ${ }^{34}$ proposed to occur through disinhibition of higher control centers. Similar patterns of ictal hyperkinetic behavior seen with diverse cortical seizure localizations $^{35-37}$ could also be explained by such a model.

Indirect evidence of a putative role for subcortical components of epileptic networks comes from observations from seizures triggered by diagnostic train cortical stimulation during SEEG: in some cases, habitual semiology can be triggered very early following onset of stimulation, many seconds before appearance of cortical discharge, in contrast with the usual pattern of spontaneous seizures observed in the same patient. ${ }^{38}$ This finding could suggest a different mode of synchronization in some seizures triggered by stimulation, in which more rapid activation of subcortical portions of the epileptic network could give rise to early emergence of semiology. This hypothesis is based on the idea that ictal behavior patterns may be encoded in specific functionally segregated circuits involving cortical and basal ganglia structures (discussed later).

Another approach to considering seizures within a corticosubcortical framework comes from work on stereotypies, repetitive motor patterns that may be observed in a variety of physiologic and pathologic conditions. These stereotypies may resemble repetitive behaviors occurring during seizures, including those involving prefrontal cortex. ${ }^{17}$ From animal and human studies, stereotypies are known to arise from corticostriatal network activity, in which motor learning takes place within well-defined and strictly anatomically organized corticosubcortical circuits. ${ }^{39}$ This motor 


\section{Table 2}

Examples of studies examining semiology in conjunction with signal analysis of stereoelectroencephalography

\begin{tabular}{|c|c|c|c|c|c|}
\hline $\begin{array}{l}\text { Investigators, } \\
\text { Year }\end{array}$ & $\begin{array}{l}\text { Semiological } \\
\text { Pattern }\end{array}$ & $\begin{array}{l}\text { Epilepsy } \\
\text { Localization }\end{array}$ & Main Anatomic Structures & Signal Analysis & $\begin{array}{l}\text { Change in } \\
\text { Network } \\
\text { Synchrony }\end{array}$ \\
\hline $\begin{array}{l}\text { Bartolomei } \\
\text { et al, }{ }^{51} 2002\end{array}$ & Humming & Temporal lobe & STG, prefrontal cortex & $\begin{array}{l}\text { Rhythmic discharge over STG ( } 6 \text { or } \\
15 \mathrm{~Hz} \text { ). Increased coherence between } \\
\text { STG and prefrontal cortex }\end{array}$ & Increased \\
\hline $\begin{array}{l}\text { Bartolomei } \\
\text { et al, }{ }^{52} 2005\end{array}$ & Fear behavior & Prefrontal cortex & $\begin{array}{l}\text { Ventromesial orbitofrontal cortex, } \\
\text { anterior cingulate, amygdala (limbic } \\
\text { system) }\end{array}$ & $\begin{array}{l}\text { Sudden loss of synchrony between } \\
\text { orbitofrontal cortex and amygdala at } \\
\text { seizure onset/clinical onset }\end{array}$ & Decreased \\
\hline $\begin{array}{l}\text { Bartolomei } \\
\text { et al, }{ }^{54} 2012\end{array}$ & Déjà vu & $\begin{array}{l}\text { Mesial temporal } \\
\text { lobe }\end{array}$ & Rhinal cortices, hippocampus & $\begin{array}{l}\text { Increased high-frequency EEG signal } \\
\text { correlation between mesial temporal } \\
\text { structures in seizures producing déjà } \\
\text { vu }\end{array}$ & Increased \\
\hline $\begin{array}{l}\text { Lambert et al, } \\
2012\end{array}$ & $\begin{array}{l}\text { Impaired } \\
\text { consciousness }\end{array}$ & Parietal lobe & $\begin{array}{l}\text { Superior and inferior parietal lobules, } \\
\text { precuneus, parietal operculum, } \\
\text { supplementary motor area }\end{array}$ & $\begin{array}{l}\text { Increased synchrony was associated } \\
\text { with progressively greater degrees of } \\
\text { altered responsiveness. A statistically } \\
\text { significant nonlinear relationship was } \\
\text { found between h2 values and degree } \\
\text { of alteration of consciousness, } \\
\text { suggesting a threshold effect }\end{array}$ & Increased \\
\hline $\begin{array}{l}\text { Aupy et al, }{ }^{56} \\
2018\end{array}$ & $\begin{array}{l}\text { Oroalimentary } \\
\text { automatisms }\end{array}$ & Temporal lobe & $\begin{array}{l}\text { Medial basal temporal lobe, opercular } \\
\text { cortex }\end{array}$ & $\begin{array}{l}\text { Increased coherence occurred between } \\
\text { mediobasal temporal structures and } \\
\text { insulo-opercular cortex before onset } \\
\text { of rhythmic chewing movements }\end{array}$ & Increased \\
\hline
\end{tabular}

Abbreviation: STG, superior temporal gyrus. 


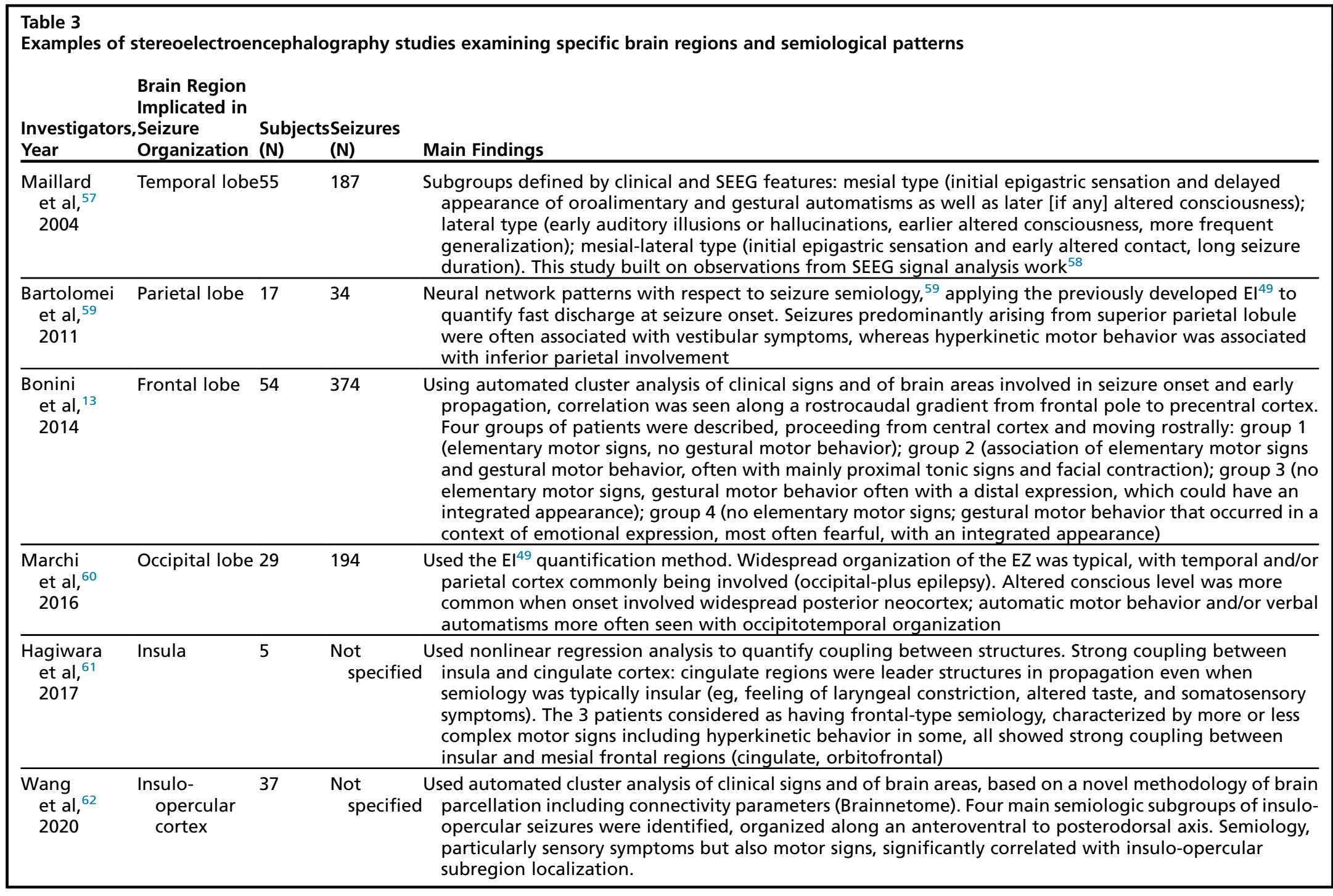



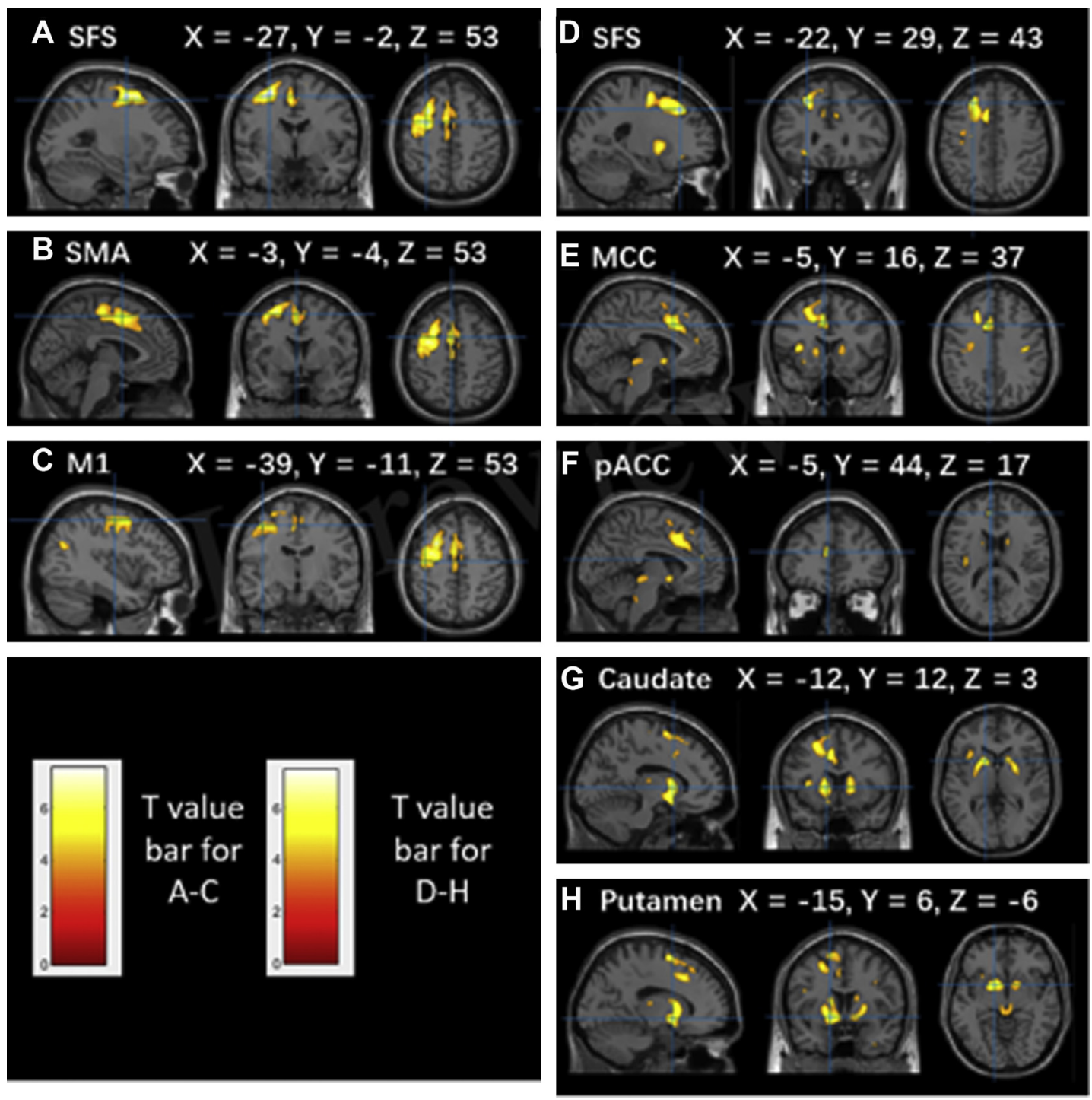

Fig. 5. A study of FCD in superior frontal sulcus (SFS) using quantified analysis of seizure discharge showed an anteroposterior gradient of semiological expression, with seizures arising from the posterior portion of SFS (group 1) showing elementary motor signs, whereas those arising from anterior portions of SFS (group 2) showed complex motor behavior. The metabolism of patients with SFS epilepsy is compared with that of healthy controls. Brain areas with decreased glucose metabolism are superimposed on the MNI152 template $(P<.001)$. The color scale indicates Tscores. Note that PET images in patients with right-sided lesions are all horizontally flipped to the left side. PET data revealed different patterns of hypometabolic areas in the 2 groups. $(A-C)$ Significant hypometabolism in the SFS, supplementary motor area (SMA), precentral gyrus in group 1. (D-H) Significant hypometabolism in the SFS, middle cingulate cortex $(\mathrm{MCC})$, pregenual anterior cingulate cortex (pACC), caudate, and putamen in group 2 . This finding suggests different pathways of propagation that may be relevant to semiological mechanisms, basal ganglia involvement being associated with seizures characterized by complex motor behavioral expression. (From Zhang C, Zhao B-t, McGonigal A, et al. Superior frontal sulcus focal cortical dysplasia type II: an MRI, PET and quantified SEEG study. Front Neurol. 2019;10:1253.)

learning also seems relevant to the generally reproducible nature of semiology seen for individual patients, because some aspects of seizure expression may be learned by progressively reinforcing network activity (via neuroplasticity) within these motor loops.
Taken together, these data suggest a possible role for specific corticobasal ganglia circuits in which certain semiological patterns might be encoded and then reactivated in each seizure, possibly through altered inhibition at basal ganglia level. ${ }^{40}$ Clinical expression might depend not only 
on cortical localization of discharge in terms of topographic connectivity with specific basal ganglia structures but also temporal features of the discharge, as previously discussed. This possibility provides an anatomic and physiologic theoretic framework with which to further investigate the neural basis of complex behaviors during seizures. However, these hypotheses remain challenging to test using SEEG because of sampling limitations, especially in terms of subcortical data. Future work combining whole-brain neuroimaging data (eg, functional MRI, PET) with SEEG recordings (Fig. 5) could help elucidate this domain, especially using multimodal modelization approaches. ${ }^{18,41}$

\section{ICTAL VERSUS INTERICTAL SEMIOLOGY?}

Although the term semiology usually refers to seizure-related clinical change, epilepsy is also characterized by high prevalence of interictal cognitive and psychiatric comorbidities. Although this is an underexplored domain, it seems likely that these symptoms at least partly reflect brain network dysfunction that has some relation to the EZ. Disruption of functional (default mode, salience) networks can be shown in focal epilepsies. ${ }^{42}$ Some clinical examples suggest that interictal dysfunction may directly involve the same networks that produce seizures. For example, a group of patients with prefrontal epilepsy presented severe antisocial behavioral problems that disappeared following successful epilepsy surgery. ${ }^{43}$ Study of interictal semiology and its relation to ictal semiology and epileptic networks represents an interesting avenue for future research.

\section{SUMMARY}

Understanding of the neural basis of seizure semiology remains a major challenge in epileptology, limiting optimal evaluation of some patients in a presurgical perspective, particularly for seizures involving complex motor behaviors, emotional change, and/or altered consciousness. This area seems ripe for development, because better knowledge of neural networks subserving behavioral expression during seizures could greatly inform exploration strategy in presurgical evaluation. More generally in neuroscience, understanding the brain-behavior relationship may require a move toward more behaviorally driven studies. ${ }^{44,45}$ Technological advances could allow quantification of semiology by automated methods (eg, video analysis, movement quantification). ${ }^{15,46}$ This ability could facilitate research efforts based on multimodal modelization of epilepsy, ${ }^{7,19}$ which are currently not powered to take account of behavioral data. ${ }^{18}$ Improved knowledge of the interactions between cortical and subcortical parts of epileptic networks in producing behavioral change could also eventually help shape new therapeutic interventions; for example, neurostimulation targeting specific deep brain nuclei, perhaps with tailored protocols aimed at modulating synchronization, ${ }^{47}$ which could potentially ameliorate the most disabling semiological symptoms of epileptic seizures. $^{48}$

\section{ACKNOWLEDGMENTS}

Many thanks to all colleagues and collaborators in the department of Clinical Neurophysiology and Institute of Neurological Systems, Aix-Marseille University, in particular Professor Fabrice Bartolomei and Dr Viktor Jirsa. I express my thanks to Professor Patrick Chauvel for helpful discussion. I thank also Professor William W. Lytton and Dr Kai Zhang for kind permission to reproduce figures. This article has been written within the Federation Hospitalo-Universitaire (FHU) EPINEXT thanks to the support of the $A^{*}$ MIDEX project (ANR-11IDEX-0001-02) funded by the Investissements d'Avenir French Government program managed by the French National Research Agency (ANR).

\section{DISCLOSURE}

The author has nothing to disclose.

\section{REFERENCES}

1. Darwin C. The expression of the emotions in man and animals. London, UK: John Murray; 1872.

2. James W. The principles of psychology, Vol. 1. New York: Henry Holt; 1890.

3. Merleau-Ponty M. Phénoménologie de la Perception. Paris, France: Éditions Gallimard, Routledge \& Kegan Paul; 1945.

4. Wilson M. Six views of embodied cognition. Psychon Bull Rev 2002;9(4):625-36.

5. Kramer MA, Cash SS. Epilepsy as a disorder of cortical network organization. Neuroscientist 2012; 18(4):360-72.

6. Bassett DS, Sporns O. Network neuroscience. Nat Neurosci 2017;20(3):353

7. Bartolomei F, Lagarde S, Wendling F, et al. Defining epileptogenic networks: contribution of SEEG and signal analysis. Epilepsia 2017;58(7):1131-47.

8. Jirsa VK, Stacey WC, Quilichini PP, et al. On the nature of seizure dynamics. Brain 2014;137(8): 2210-30.

9. Gastaut H. Clinical and electroencephalographical classification of epileptic seizures. Epilepsia 1970; 11(1):102-12. 
10. Fisher RS, Cross JH, French JA, et al. Operational classification of seizure types by the International League Against Epilepsy: Position Paper of the ILAE Commission for Classification and Terminology. Epilepsia 2017;58(4):522-30.

11. de Carvalho Aguiar PM, Ozelius LJ. Classification and genetics of dystonia. Lancet Neurol 2002;1(5): 316-25.

12. Seneviratne U, Rajendran D, Brusco M, et al. How good are we at diagnosing seizures based on semiology? Epilepsia 2012;53(4):e63-6.

13. Bonini F, McGonigal A, Trébuchon A, et al. Frontal lobe seizures: from clinical semiology to localization. Epilepsia 2014;55:264-77.

14. Dal-Cól M, Terra-Bustamante $\mathrm{V}$, Velasco $\mathrm{T}$, et al. Neuroethology application for the study of human temporal lobe epilepsy: from basic to applied sciences. Epilepsy Behav 2006;8(1):149-60.

15. Ahmedt-Aristizabal D, Fookes C, Dionisio S, et al. Automated analysis of seizure semiology and brain electrical activity in presurgery evaluation of epilepsy: A focused survey. Epilepsia 2017;58(11):1817-31.

16. Chauvel P, McGonigal A. Emergence of semiology in epileptic seizures. Epilepsy Behav 2014;38:94-103.

17. McGonigal A, Chauvel P. Prefrontal seizures manifesting as motor stereotypies. Mov Disord 2014; 29(9):1181-5.

18. Jirsa VK, Proix T, Perdikis D, et al. The virtual epileptic patient: individualized whole-brain models of epilepsy spread. Neuroimage 2017;145:377-88.

19. Lytton WW, Arle J, Bobashev G, et al. Multiscale modeling in the clinic: diseases of the brain and nervous system. Brain Inform 2017;4(4):219-30.

20. Jackson JH. Selected writings of John Hughlings Jackson: on epilepsy and epileptiform convulsions. London: Hodder and Stoughton; 1931.

21. Jefferson G. Jacksonian Epilepsy: A background and a post-script. Postgrad Med J 1935;11(114): 150.

22. Maillard L, Gavaret M, Régis J, et al. Fast epileptic discharges associated with ictal negative motor phenomena. Clin Neurophysiol 2014;125(12):2344-8.

23. Catani M, Dell'Acqua F, Vergani F, et al. Short frontal lobe connections of the human brain. Cortex 2012; 48(2):273-91.

24. Schmahmann J, Pandya D. Fiber pathways of the brain. New York: Oxford University Press; 2006.

25. Rosenow F, Lüders H. Presurgical evaluation of epilepsy. Brain 2001;124(9):1683-700.

26. Guye M, Régis J, Tamura M, et al. The role of corticothalamic coupling in human temporal lobe epilepsy. Brain 2006;129(Pt 7):1917-28.

27. Uhlhaas PJ, Singer W. Neural synchrony in brain disorders: relevance for cognitive dysfunctions and pathophysiology. Neuron 2006;52(1):155-68.

28. Blume WT, Lüders HO, Mizrahi E, et al. Glossary of descriptive terminology for ictal semiology: report of the ILAE task force on classification and terminology. Epilepsia 2001;42(9):1212-8.

29. Rolnick J, Parvizi J. Automatisms: bridging clinical neurology with criminal law. Epilepsy Behav 2011; 20(3):423-7.

30. Bulacio JC, Chauvel P, McGonigal A. Stereoelectroencephalography: Interpretation. J Clin Neurophysiol 2016;33(6):503-10.

31. Grinenko O, Li J, Mosher JC, et al. A fingerprint of the epileptogenic zone in human epilepsies. Brain 2018;141(1):117-31.

32. Gastaut H, Broughton RJ. Epileptic seizures: clinical and electrographic features, diagnosis and treatment. Springfield, IL: Charles C. Thomas Publisher; 1972.

33. Tassinari CA, Cantalupo G, Högl B, et al. Neuroethological approach to frontolimbic epileptic seizures and parasomnias: The same central pattern generators for the same behaviours. Rev Neurol (Paris) 2009; 165(10):762-8.

34. Tassinari CA, Rubboli G, Gardella E, et al. Central pattern generators for a common semiology in fronto-limbic seizures and in parasomnias. A neuroethologic approach. Neurol Sci 2005;26(Suppl 3): s225-32.

35. Vaugier L, Aubert S, McGonigal A, et al. Neural networks underlying hyperkinetic seizures of "temporal lobe" origin. Epilepsy Res 2009;86(2-3):200-8.

36. Ryvlin P, Minotti L, Demarquay G, et al. Nocturnal hypermotor seizures, suggesting frontal lobe epilepsy, can originate in the insula. Epilepsia 2006;47(4):755-65.

37. Gibbs SA, Proserpio P, Francione S, et al. Seizure duration and latency of hypermotor manifestations distinguish frontal from extrafrontal onset in sleeprelated hypermotor epilepsy. Epilepsia 2018;59(9): e130-4.

38. McGonigal A, Lagarde S, Trébuchon-Dafonseca A, et al. Early onset motor semiology in seizures triggered by cortical stimulation during SEEG. Epilepsy Behav 2018;88:262-7.

39. Graybiel AM. Habits, rituals, and the evaluative brain. Annu Rev Neurosci 2008;31:359-87.

40. Jahanshahi M, Obeso I, Rothwell JC, et al. A frontostriato-subthalamic-pallidal network for goaldirected and habitual inhibition. Nat Rev Neurosci 2015;16(12):719-32.

41. Proix T, Bartolomei F, Guye M, et al. Individual brain structure and modelling predict seizure propagation. Brain 2017;140(3):641-54.

42. Besson P, Bandt SK, Proix T, et al. Anatomic consistencies across epilepsies: a stereotactic-EEG informed high-resolution structural connectivity study. Brain 2017;140(10):2639-52.

43. Trebuchon A, Bartolomei F, McGonigal A, et al. Reversible antisocial behavior in ventromedial prefrontal lobe epilepsy. Epilepsy Behav 2013;29(2): 367-73. 
44. Krakauer JW, Ghazanfar AA, Gomez-Marin A, et al. Neuroscience needs behavior: correcting a reductionist Bias. Neuron 2017;93(3):480-90.

45. Jirsa VK, Mclntosh AR, Huys R. Grand Unified Theories of the brain need better understanding of behavior: the two-tiered emergence of function. Ecol Psychol 2019;31(3):152-65.

46. Hou J-C, Thonnat M, Huys R, et al. Rhythmic rocking stereotypies in frontal lobe seizures: A quantified video study. Neurophysiol Clin 2020.

47. Filipescu C, Lagarde S, Lambert I, et al. The effect of medial pulvinar stimulation on temporal lobe seizures. Epilepsia 2019;60(4):e25-30.

48. Gummadavelli A, Motelow JE, Smith N, et al. Thalamic stimulation to improve level of consciousness after seizures: evaluation of electrophysiology and behavior. Epilepsia 2015;56(1):114-24.

49. Bartolomei F, Chauvel P, Wendling F. Epileptogenicity of brain structures in human temporal lobe epilepsy: a quantified study from intracerebral EEG. Brain 2008;131(Pt 7):1818-30.

50. Chassoux F, Devaux B, Landré E, et al. Stereoelectroencephalography in focal cortical dysplasia A 3D approach to delineating the dysplastic cortex. Brain 2000;123(8):1733-51.

51. Bartolomei F, Wendling F, Vignal JP, et al. Neural networks underlying epileptic humming. Epilepsia 2002;43(9):1001-12.

52. Bartolomei F, Trébuchon A, Gavaret M, et al. Acute alteration of emotional behaviour in epileptic seizures is related to transient desynchrony in emotion-regulation networks. Clin Neurophysiol 2005;116(10):2473-9.

53. Arthuis M, Valton L, Régis J, et al. Impaired consciousness during temporal lobe seizures is related to increased long-distance cortical-subcortical synchronization. Brain 2009;132(Pt 8):2091-101.

54. Bartolomei F, Barbeau EJ, Nguyen T, et al. Rhinalhippocampal interactions during déjà vu. Clin Neurophysiol 2012;123(3):489-95.

55. Lambert I, Arthuis M, McGonigal A, et al. Alteration of global workspace during loss of consciousness: a study of parietal seizures. Epilepsia 2012;53(12): 2104-10.

56. Aupy J, Noviawaty I, Krishnan B, et al. Insulo-opercular cortex generates oroalimentary automatisms in temporal seizures. Epilepsia 2018;59(3):583-94.

57. Maillard L, Vignal JP, Gavaret M, et al. Semiologic and electrophysiologic correlations in temporal lobe seizure subtypes. Epilepsia 2004;45(12):1590-9.

58. Bartolomei F, Wendling F, Vignal JP, et al. Seizures of temporal lobe epilepsy: identification of subtypes by coherence analysis using stereo-electro-encephalography. Clin Neurophysiol 1999;110(10):1741-54.

59. Bartolomei F, Gavaret M, Hewett R, et al. Neural networks underlying parietal lobe seizures: a quantified study from intracerebral recordings. Epilepsy Res 2011;93(2-3):164-76.

60. Marchi A, Bonini F, Lagarde S, et al. Occipital and occipital "plus" epilepsies: A study of involved epileptogenic networks through SEEG quantification. Epilepsy Behav 2016;62:104-14.

61. Hagiwara K, Jung J, Bouet R, et al. How can we explain the frontal presentation of insular lobe epilepsy? The impact of non-linear analysis of insular seizures. Clin Neurophysiol 2017;128(5):780-91.

62. Wang $H$, McGonigal A, Zhang $K$, et al. Semiologic subgroups of insulo-opercular seizures based on connectional architecture atlas. Epilepsia 2020. In press. 